\title{
ORAL HEALTH STATUS AND TREATMENT NEEDS IN HEARING IMPAIRED AND VISUALLY IMPAIRED CHILDREN IN MANSOURA CITY, EGYPT
}

\author{
Rasha Ramadan*
}

\begin{abstract}
Aims: this study was carried out to assess oral health status and treatment needs among a group of hearing impaired and visually impaired children in Mansoura city, Egypt.

Methodology: A cross sectional study design was conducted. Total of 130 hearing impaired and 120 of visually impaired children were included in addition to 130 of normal children. The diagnosis of dental caries was done according to the World Health Organization (WHO) criteria using dft and DMFT indices. Oral hygiene was assessed using Simplified Oral Hygiene Index (OHI-S). Gingivitis was evaluated by Papillary, Marginal and Attached (PMA) Index. Also, treatment need was specified using Unmet Treatment Need (UTN) index

Results: It was found that the caries prevalence and experience was significantly higher among visually impaired children $(73.3 \%, 5.33 \pm 4.32)$ and hearing impaired children $(61.5 \%, 4.73 \pm 4.38)$ than normal children $(46.2 \%, 1.07 \pm 1.80)$ ( $\mathrm{p}$ value $\leq 0.05$ ). In addition, there was a statistically significant difference in median scores of PMA index, median scores of OHIS index and percentage of unmet treatment needs among the study groups ( $\mathrm{p}$ value $\leq 0.05$ ).

Conclusion: the caries prevalence and severity was higher among visually impaired and hearing impaired children than normal children. They also suffered from more gingivitis, poor oral hygiene and higher percentage of unmet treatment needs compared to normal children.
\end{abstract}

KEY WORDS: Visually impaired child, hearing impaired child, oral health status

\section{INTRODUCTION}

Oral health status of children has great impact on the general health, well-being and quality of life. Children with special needs are a special group of patients with different forms of systemic disorders such as developmental, mental, sensory, physical, cognitive, or behavioral, emotional impairment or a limiting condition that needs health care intervention, medical management, and specialized services or programs. There is limited

* Assistant Professor of Dental Public Health and Preventive Dentistry, Pediatric Dentistry and Dental Public Health Department, Faculty of Dentistry, Mansoura University, Mansoura 
motor and sensory coordination among children with disabilities; most of them cannot take care for themselves and must depend on their caregivers or parents for general care. ${ }^{(1)}$

Children with developmental impairment mainly have a complex unmet health care treatment needs. Disabled Children with worse conditions and from families with low socioeconomic status are suffering from high unmet dental needs and limited access to health care. It was found that dental treatment is the most prominent unmet health need of the children with any forms of impairment. ${ }^{(2)}$

Hearing impairment and visual impairment create a high proportion among all disabled children. It was reported that, hearing impairment is the most prominent sensory disability during childhood. (3) The prevalence of visual impairment among children is 1.4 million worldwide, most of them live in low income countries of Asia and Africa. ${ }^{(4-6)}$ these disabilities has a great effect on social, emotional, and psychomotor development of children. ${ }^{(5)}$

Children with hearing or visually impairment are suffering from high level of oral diseases, due to their actual impairment or economic limitation or social factors, or even because their parents find difficulty in performing essential daily oral hygiene regimen. ${ }^{(7)}$ Daily oral hygiene practices are more difficult than oral care of children with normal abilities, who commonly have the ability to perform their oral health care by themselves. In contrary to that, disabled children may be dependent on others to achieve their routinely oral care activities. ${ }^{(8)}$

Oral disease is a major health problem for children with disabilities. ${ }^{(3)}$ They suffered from an elevated prevalence and severity of oral disease when compared to the healthy children. ${ }^{(9)}$ They have high percentage of dental caries, missing teeth, prolonged retention of primary teeth, misaligned or supernumerary teeth, malocclusion, and periodontal disease. All these oral diseases are significant indicators of poor oral health which has negative impact on the ability of the child to chew and enjoy food, digestion, nutrition, facial shape and speech or in other words their quality of life ${ }^{(10,11)}$

There are many studies ${ }^{(12-16)}$ worldwide reported Poor oral hygiene, gingivitis and periodontitis among visually impaired children. These patients mainly have poor and insufficient knowledge about oral health. Attaining of acceptable oral hygiene is considered one of the most difficult tasks for visually impaired children. ${ }^{(17)}$

Liu et al., 2019(18) assessed the oral health status to the school children with vision impairment in China. They found that their participants had a high prevalence of dental caries, periodontal diseases, and sever malocclusion.

Rezaei et al.,2019 ${ }^{(19)}$ evaluated the oral health status and treatment needs of children with hearing and vision impairment. The result revealed that, those children had high level of tooth decay, particularly in deciduous teeth, an elevated percentage of the children and needed treatment. In comparison to their peers, these group of children had lower level of oral health

Various studies on the oral health status of the normal children have been carried out worldwide; however, limited information is available on the oral health of the hearing impaired and visually impaired children particularly in Egypt. However, the data about oral health status and treatment needs for children with special needs will help to obtain baseline data to understand oral health needs of those children and consequently the appropriate preventive measures will be recommended and undertaken. For that reason, this study was conducted to assess oral health status and treatment needs among a group of hearing impaired and visually impaired children in Mansoura city, Egypt.

\section{MATERIALS AND METHODS}

This study was conducted after approval of Ethical Committee of Faculty of Dentistry, Mansoura University under code number (A21030821). A detailed information on the study was provided 
to all the participated children. Verbal assent was obtained from the children prior to the clinical examination. Additionally, an informed consent was sent to the parents prior to clinical examination. Children who unwell to participates were excluded from the study. After the examination, children in need of dental treatment were referred to the outpatient clinic of Pediatric Dentistry and Dental Public Health department, Faculty of Dentistry, Mansoura University. All the collected data was coded and safeguarded with high privacy.

A descriptive cross sectional study design among hearing impaired and visually impaired children was conducted. All hearing impaired students at Al-Amal school for deaf and dumb in addition to all the visually impaired students at Al-Nour school for blind at primary and preparatory stages were attended to be included in the study. Total number of hearing impaired children who returned signed consent forms and considered valid for the study was 130 children while the total number of visually impaired children was 120 children. The age of children ranged from 7 to15 years old. A number of 130 Children who were free from any systemic disease were included as a control group. Healthy children had the same age range, and matched in gender and socioeconomic status to the study group. Control group was selected from governmental schools, Mansoura city using convenience sampling technique.

Clinical examination of all school children was done by single trained and calibrated examiner. The consistency of examination was ensured by twice examination of 20 children by the same examiner using the same indices used in this study. The results of the two examinations were compared and the agreement Kappa value ${ }^{(20)}$ was high. Intra-examiner reliability was calculated and Cohen Kappa score was 0.95 .

Clinical examination was performed at school in an ordinary chair facing natural light and a source of artificial white light was also used for all children.
Clinical examination was done with disposable mirrors and probes.

Diagnosis of dental caries was performed according to the (WHO) ${ }^{(21)}$ criteria using dft index for deciduous teeth and DMFT index for permanent teeth. ${ }^{(22,23)}$ Tooth was scored decayed if there is undermining, softening, cavitation, temporary filling, recurrent caries and/ or remaining root.

Gingivitis was assessed using Papillary, Marginal and Attached (PMA) Index. ${ }^{(23)}$ gingival inflammation for each child was assessed using; score (0) in case of normal gingiva with no change in color or appearance while, score (1) was recorded in presence of any sign of inflammation.

Oral hygiene was assessed using Simplified Oral Hygiene Index $(\mathrm{OHI}-\mathrm{S})^{(24)}$. It consists of two components: the simplified debris index (DI-S) and the simplified calculus index (CI-S) that based on extension of debris or calculus on six preselected teeth surfaces. The index teeth are $(16,11$, $26,36,31,46)$ All teeth were examined from the facial surface except the mandibular molars were examined from the lingual surface. ${ }^{(24)}$

The examined teeth surfaces take scores according to the following scores (table 1) OHI-S for each child was calculated by adding the total DI-S scores and total CI-S index of the selected teeth. Oral hygiene level was assessed as good or fair or poor according to the interpretation of total S-OHI scores (table 2)

The unmet treatment need among participated children was also specified using Unmet Treatment Need (UTN) index ${ }^{(25)}$.

The data were statistically analyzed using SPSS version 21(SPSS, Inc., Chicago, IL, USA). The normal distribution of data was assessed by Kolmogorov-Smirnov test. Chi-square test was the test of significance for qualitative data. While for quantitative data, One-Way ANOVA test was used for parametric data and Kruskal- Wallis test for nonparametric data. The statistically significance was considered at $\mathrm{P}$-value $\leq 0.05$. 
TABLE (1): Simplified Oral Hygiene Index Scores (OHI-S)

\begin{tabular}{|c|c|c|}
\hline Scores & Debris index (D I) & Calculus index (C I) \\
\hline $\mathbf{0}$ & No debris or stain present. & No calculus present. \\
\hline $\mathbf{1}$ & $\begin{array}{c}\text { Soft debris covering not more than one third of } \\
\text { tooth surface, or presence of extrinsic stains }\end{array}$ & $\begin{array}{c}\text { Supra gingival calculus covering not more than one third } \\
\text { of tooth surface }\end{array}$ \\
\hline $\mathbf{2}$ & $\begin{array}{c}\text { Soft debris covering more than one third, but not } \\
\text { more than two third of the exposed tooth surface. }\end{array}$ & $\begin{array}{c}\text { Supra gingival calculus covering more than one } \\
\text { third but not more than two third, or the presence of } \\
\text { individual flecks of sub gingival calculus }\end{array}$ \\
\hline $\mathbf{3}$ & Soft debris covering more than two thirds of \\
exposed tooth surface & $\begin{array}{c}\text { Supra gingival calculus covering more than two third } \\
\text { of tooth surface or continuous band of sub gingival } \\
\text { calculus or both }\end{array}$ \\
\hline
\end{tabular}

TABLE (2): OHI-S Values and Interpretations.

\begin{tabular}{|c|c|}
\hline OHI-S values & Interpretations \\
\hline $0-1.2$ & Good oral hygiene \\
\hline $1.3-3$ & Fair oral hygiene \\
\hline $3.1-6$ & Poor oral hygiene \\
\hline
\end{tabular}

\section{RESULTS}

Table (3) shows caries prevalence and experience among the study groups. It was found that caries prevalence and experience was higher among visually impaired children $(73.3 \%, 5.33 \pm 4.32)$ and hearing impaired children $(61.5 \%, 4.73 \pm 4.38)$ than normal children $(46.2 \%, 1.07 \pm 1.80)$ and these difference were statistically significant ( $\mathrm{p}$ value $\leq 0.05)$

Table (4) shows the gingival condition and oral hygiene status among study groups. It was found that the median of PMA scores among hearing impaired and visually impaired children were (26) and (31) respectively while in control group was (24), a significant statistical difference was found ( $\mathrm{p}$ value is 0.002 ).

Regarding oral hygiene, it was found that there was statistically significant difference between median scores of OHIS index among study groups ( $p$ value $<0.001)$. The scores were higher among visually impaired children (2.41) than hearing impaired children (2.33) with no statistical significance.

TABLE (3): Caries prevalence and experience among the study groups

\begin{tabular}{|c|c|c|c|c|c|c|c|}
\hline \multirow{2}{*}{ Groups } & \multicolumn{2}{|c|}{ Caries prevalence } & \multirow{2}{*}{$\begin{array}{c}\text { P value of } \chi^{2} \\
\text { test }\end{array}$} & \multirow{2}{*}{$\begin{array}{c}\text { DMFT } \\
\left(\mathrm{X}^{-} \pm \mathrm{SD}\right)\end{array}$} & \multirow{2}{*}{ P1 value } & \multirow{2}{*}{$\begin{array}{c}\text { dft } \\
\left(X^{-} \pm \text {SD }\right)\end{array}$} & \multirow{2}{*}{ P1 value } \\
\hline & & $\%$ & & & & & \\
\hline $\begin{array}{l}\text { Hearing impaired children } \\
\qquad \mathrm{N}=130\end{array}$ & 80 & $61.5 \%$ & \multirow{3}{*}{$(0.041) *$} & $4.73 \pm 4.38$ & \multirow{3}{*}{$<0.001^{*}$} & $3.96 \pm 3.17$ & \multirow{3}{*}{$<0.001^{*}$} \\
\hline $\begin{array}{l}\text { Visually impaired children } \\
\qquad \mathrm{N}=120\end{array}$ & 88 & $73.3 \% \%^{\#}$ & & $5.33 \pm 4.32^{\#}$ & & $4.33 \pm 3.10^{\#}$ & \\
\hline $\begin{array}{l}\text { Control group } \\
\qquad \mathbf{N}=130\end{array}$ & 60 & $46.2 \%$ & & $1.07 \pm 1.80^{\#+3 x}$ & & $2.00 \pm 2.59$ & \\
\hline
\end{tabular}


Table (5) shows oral hygiene level among the study groups. It was found that the oral hygiene status was better among the control group than the hearing impaired and visually impaired children. Poor oral hygiene was reported among $75.7 \%$ of hearing impaired and $63.2 \%$ of visually impaired children while in control group it was reported among only $14.6 \%$ ( $\mathrm{p}$ value $<0.001$ ).

Table (6) shows the different unmet treatment needs among study groups. It was found that $15.4 \%$ of hearing impaired children and $13.3 \%$ of visually impaired children don't need treatment. While, 29.2\% children in control group don't need treatment, in addition to that; there was a statistically significant difference between study groups in treatment needs for prophylaxis and restoration $(\mathrm{p} \leq 0.05)$. There was no significant difference between treatment needs for extraction $(p=0.265)$

TABLE (4) : Gingival condition using PMA index and oral hygiene status using OHIS index among the study groups:

\begin{tabular}{|c|c|c|c|c|}
\hline Groups & $\begin{array}{c}\text { PMA } \\
\text { median (min-max) }\end{array}$ & $\begin{array}{c}\text { DI } \\
\text { Median (min-max) }\end{array}$ & $\begin{array}{c}\text { CI } \\
\text { Median (min-max) }\end{array}$ & $\begin{array}{c}\text { OHIS } \\
\text { Median(min-max) }\end{array}$ \\
\hline $\begin{array}{l}\text { Hearing impaired children } \\
\qquad \mathrm{N}=130\end{array}$ & $26(3-56)$ & $1.66(0.66-3)^{\# t}$ & $0.41(0-2)$ & $2.33(0.66-5)^{3}$ \\
\hline $\begin{array}{l}\text { Visually impaired children } \\
\qquad \mathrm{N}=120\end{array}$ & $31(6-66)^{\#}$ & $1.73(0.83-3)^{\# \&}$ & $0.66(0-2)^{3}$ & $2.41(0.83-5)^{\#}$ \\
\hline $\begin{array}{l}\text { Control group } \\
\qquad \mathrm{N}=130\end{array}$ & $24(0-42)$ \#站 & $1.33(1-2.17)^{8}$ & $0.33(0-1.17)^{*}$ & $1.66(1-3)^{\#-6 x}$ \\
\hline $\begin{array}{c}\text { P value of Kruskal Wallis } \\
\text { test }\end{array}$ & $0.002 *$ & $<0.001 *$ & $<0.001 *$ & $<0.001 *$ \\
\hline
\end{tabular}

$N \leftrightarrow$ number of the examined children

$*_{\leftrightarrow}$ Significant difference $(p \leq 0.05)$

$\#, \&,+$ similar symbols mean Significant difference between groups $(p<0.05)$

TABLE (5): Oral hygiene level among the study groups

\begin{tabular}{|c|c|c|c|}
\hline Groups & $\begin{array}{c}\text { Good oral hygiene } \\
\mathbf{n}(\%)\end{array}$ & $\begin{array}{c}\text { Fair oral hygiene } \\
\mathbf{n}(\%)\end{array}$ & $\begin{array}{c}\text { Boor oral hygiene } \\
\mathbf{n}(\mathbf{\%})\end{array}$ \\
\hline $\begin{array}{c}\text { Hearing impaired children } \\
\mathbf{N}=\mathbf{1 3 0}\end{array}$ & $12(9.2 \%)^{*}$ & $43(33.1 \%)^{*}$ & $75(57.7 \%)^{*}$ \\
\hline $\begin{array}{c}\text { Visually impaired children } \\
\mathbf{N}=\mathbf{1 2 0}\end{array}$ & $19(15.8 \%)^{*}$ & $25(20.8 \%)$ & $76(63.2 \%)^{\#}$ \\
\hline $\begin{array}{c}\text { Control group } \\
\mathbf{N}=\mathbf{1 3 0}\end{array}$ & $88(67.7 \%)^{*}$ & $23(17.7 \%)^{*}$ & $19(14.6 \%)^{*}$ \\
\hline P value of $\chi^{2}$ test & $<0.001^{*}$ & $0.03^{*}$ & $<0.001^{*}$ \\
\hline
\end{tabular}

$N \leftrightarrow$ number of the examined children

$*_{\leftrightarrow \text { Significant difference }(p \leq 0.05)}$

$\#, \&, \leftrightarrow$ similar symbols mean Significant difference between groups ( $p \leq 0.05)$ 
TABLE (6): Different treatment needs among the study groups

\begin{tabular}{|c|c|c|c|c|}
\hline Groups & $\begin{array}{c}\text { No ttt needs } \\
\text { n }(\%)\end{array}$ & $\begin{array}{c}\text { Prophylaxis ttt needs } \\
\text { n (\%) }\end{array}$ & $\begin{array}{c}\text { Restoration ttt needs } \\
\mathbf{n}(\%)\end{array}$ & $\begin{array}{c}\text { Extraction ttt needs } \\
\text { n (\%) }\end{array}$ \\
\hline $\begin{array}{l}\text { Hearing impaired children } \\
\qquad N=130\end{array}$ & $20(15.4 \%)^{\#}$ & $60(46.1 \%)^{\#}$ & $80(61.5 \%)^{\#}$ & $15(11.5 \%)$ \\
\hline $\begin{array}{l}\text { Visually impaired children } \\
\qquad \mathrm{N}=120\end{array}$ & $16(13.3 \%)^{x}$ & $66(55 \%)$ & $88(73.3 \%)^{2}$ & $18(15 \%)$ \\
\hline $\begin{array}{c}\text { Control group } \\
\qquad \mathbf{N}=\mathbf{1 3 0}\end{array}$ & $38(29.2 \%)^{\#-2}$ & $40(30.8 \%)^{\#+\frac{1}{\alpha}}$ & $50(38.5 \%)^{\#-2}$ & $10(7.7 \%)$ \\
\hline$P$ value of $\chi^{2}$ test & $0.019 *$ & $0.045^{*}$ & $0.010^{*}$ & 0.265 \\
\hline
\end{tabular}

\section{DISCUSSION}

Vision and hearing are the most important ways for communication, and any impairment in early childhood can have negative effects on physical, neurological, cognitive and emotional development which consequently affect on both oral and general health of the child. ${ }^{(17)}$ Those children have a higher prevalence and severity of oral disease when compared to the general population. ${ }^{(9)}$

Concerning dental caries; this study revealed high prevalence of dental caries among visually impaired and hearing- impaired children comparing to control group. Those children are partially or completely dependent on others in their daily care activities. Frequent teeth brushing cannot be performed alone, maintaining acceptable oral hygiene may be unattained which leads to high prevalence of dental caries. Additionally, the lack of knowledge about caries prevention practices may worsen the condition.

This result was in accordance with other studies which were performed to assess oral health status among deaf and blind schoolchildren worldwide and their results showed that the prevalence of dental caries were higher among hearing impaired and visually impaired schoolchildren as compared with children in the general population ${ }^{(7,18,26,27)}$
On the other hand, other studies revealed lower prevalence of dental caries than the present study. $(4,28,29)$ This discordance may be due to difference in age groups, better socio economic status, health insurance coverage of the included children in these studies.

As regards to gingival condition among study groups, it was found that visually impaired and hearing impaired children suffered from gingivitis more than children within control group. These findings were in agreement with El Deeb $2011^{(28)}$, Mariam et-al $2015^{(27)}$, Liu Lu et-al $2019^{(18)}$, Rezaei et-al $2019^{(19)}$ as their results concluded that more than half of the included blind and deaf children in their studies had gingivitis.

Referring to oral hygiene status; the results presented that $63.2 \%$ of visually impaired and $57.7 \%$ of hearing impaired children suffering from poor oral hygiene compared to only $14.6 \%$ in normal children, in addition; visually impaired and hearing impaired children had higher S.OHI scores with more calculus and debris scores than control group.

The high scores of PMA index and S.OHI index can be explained by lack of knowledge and motivation about the proper methods to maintain healthy mouth, the low priority given to oral health 
care. Furthermore; the restricted ability of visually impaired and hearing impaired children to follow instructions.

There are many studies supported that visually impaired children suffered from gingivitis and bad oral hygiene. Nirmala and Degala $2019^{(17)}$ stated that children with visual impairment are suffering from poor oral hygiene related to learning disabilities, as well as hypo-plastic teeth. Also, a high level of gingival inflammation due to inability visualize and remove the plaque was reported. Additionally, the results of other previous studies exhibited that most patients with hearing and vision impairments had fair to poor oral Hygiene level. ${ }^{(15,28,30,31)}$

In contrast to that, Mariam et-al $2015^{(27)}$ found that most of participants had good level of oral hygiene. Authors stated that their finding was better than those recorded in most previous studies. It was explained that most of children included in their study were in the primary dentition stage, while children included in other studies were mostly in the mixed and permanent dentition stages, as the mean OHI-S increased from primary dentition towards mixed dentition. ${ }^{(27)}$

Regarding to the unmet treatment needs, $(84.6 \%, 86.7 \%)$ of hearing impaired and visually impaired children respectively had un met treatment needs compared to $(70.8 \%)$ in normal children. These needs included prophylaxis, restoration and extraction.

The results of the present study highlighted the elevated unmet treatment needs among children with hearing and vision impairment. This can be explained by the high level of caries, gingivitis, and poor oral hygiene of the participants, in addition to their limited ability to complain in case of mild pain; this cause the early stage of the disease to be unrecognized. Also the low socioeconomic status of children included in this study may play a role in high percentage of unmet treatment needs.
These results were in agreement with Mariam et-al $2015^{(27)}$ who reported high percentage of Preventive and restorative treatment needs are unmet in children with hearing impairment. It was attributed to the poor oral health attitude and knowledge of the parents of these children. Additionally, Mehta et al $2015^{(32)}$ concluded that $98.7 \%$ of children with different disability required some form of dental treatment.

Moreover, the result of the present study in accordance with Rezaei et-al $2019{ }^{(19)}$ and Juma et-al $2019^{(33)}$. The results revealed that up to $41 \%$ of the subjects required oral prophylaxis, $89 \%$ restorations, $13 \%$ extractions, $20 \%$ orthodontic treatment, and $11 \%$ dental prosthesis. ${ }^{(33)}$

All findings highlighted that oral health status of children with hearing and visual impairment are poor and more attention is required to plan and perform a comprehensive oral health care program for them.

\section{CONCLUSION}

Vision and hearing impairment can increase the level of oral diseases among school children in Egypt. It was found that caries prevalence and severity was higher among visually and hearing impaired children than normal children. Impaired children also suffered from more gingivitis, poor oral hygiene and higher percentage of unmet treatment needs compared to normal children.

\section{RECOMMENDATION}

Based on the results of the present study; it is necessary to establish oral health education programs for children with visual and hearing impairment and their parents to improve their oral health knowledge and practice. Furthermore; health authorities should give special attention to perform a comprehensive preventive school based oral health program jointly with general health program. 


\section{ACKNOWLEDGMENT}

Great thanks to all staff and school children at Al-Amal school for deaf and dumb and Al-Nour school for blind for their cooperation during the study

\section{REFERENCES}

1. American Academy of Pediatric Dentistry (2012). Guideline on management of dental patients with special health care needs. Pediatr Dent; 34:160 e5.

2. Norwood K W Jr and Slayton R L. (2013). Oral Health Care for Children with Developmental Disabilities. Pediatrics; 131 (3): 614-620.

3. World Health Organization (WHO)(2009). Newborn and Infant Hearing Screening. Current Issues and Guiding Principles for Action. Geneva.

4. Reddy VK, Chaurasia K, Bhambal A, Moon N, Reddy EK (2013). A comparison of oral hygiene status and dental caries experience among institutionalized visually impaired and hearing impaired children of age between 7 and 17 years in central India. J Indian Soc Pedod Prev Dent ;31:141-145.

5. World Health Organization(2000): Preventing blindness in children. Report of a WHO/IAPB scientific meeting. WHO/PBL/00.71. Geneva: WHO.

6. Prevention of Blindness and Visual Impairment. http:// www.who.int/blindness/causes/priority/en/index4.htm.

7. Rezaei F, Mardani A, Moradi AH, Nikkerdar N (2019). Examining oral hygiene status and care needs of deaf and blind 6-12 years old exceptional school children in Kermanshah in 2015. J Family Med Prim Care ; 8:871-4.

8. Siklos S, Kerns KA (2007). Assessing the diagnostic experiences of a small sample of parents of children with autism spectrum disorders. Res Dev Disabil ;28:9-22.

9. Beange H. Caring for a vulnerable population (1996): Who will take responsibility for those getting a raw deal from the health care system? Med J ; 164:159-160.

10. Gordon SM, Dionne RA, Snyder J (1998). Dental fear and anxiety as a barrier to accessing oral health care among patients with special health care needs. Spec Care Dentist; 18:88-92.
11. Turkistani B, Elmarsafy SM (2019). Caries experience among visually impaired and normal female students aged 6-18 years in Makkah, Saudi Arabia: a comparative study. Int J Health Sci Res ; 9(12):286-292.

12. Nandini NS (2003): New insights into improving the oral health of visually impaired children. J Indian Soc Pedod Prev Dent , 21(4):142-143.

13. Ahmad MS, Jindal MK, Khan S, H (2009). Oral health knowledge, practice, oral hygiene status and dental caries prevalence among visually impaired students in residential institute of Aligarh. J Dent Oral Hyg , 1(2):022-026.

14. Shetty V, Hegde AM, Bhandary S, Rai K(2010). Oral health status of the visually impaired children-a south Indian study. J Clin Pediatr Dent, 34(3):213-216.

15. Reddy K, Sharma A(2011). Prevalence of oral health status in visually impaired children. J Indian Soc Pedod Prev Dent, 29(1):25-27.

16. Bekiroglu N, Acar N, Kargul B(2012): Caries experience and oral hygiene status of a group of visually impaired children in istanbul, Turkey. Oral Health Prev Dent, 10(1):75-81

17. SVSG Nirmala and Degala Saikrishna (2019). Oral Health and Dental Care of Children with Visual Impairment -- An Over View. EC Dental Science 18.5: 848-853.

18. Liu L, Zhang Y, Wu W, He M, Lu Z, Zhang K, Li J, Lei S, Guo S and Zhang Y (2019). Oral health status among visually impaired schoolchildren in Northeast China. BMC Oral Health; 19(63): 1-7.

19. Rezaei F, Mardani A, Moradi AH, Nikkerdar N (2019). Examining oral hygiene status and care needs of deaf and blind 6-12 years old exceptional school children in Kermanshah in 2015. J Family Med Prim Care; 8:871-874.

20. Vanbelle S (2017). Comparing dependent kappa coefficients obtained on multilevel data. Biom J; 59:1016-1034.

21. World Health Organization (2013.), Oral Health Surveys, basic method, 5thed. Geneva (WHO).

22. Hiremath SS (2011.) Indices. In: Hire math SS. Textbook of preventive and community Dentistry. $2^{\text {nd }}$ ed. India: Elsevier;198-221.

23. Soben P (2008). Essential of Preventive and Community Dentistry, 3rd ed.: Arya (Medi). 147-148.

24. Greene JC, Vermillion JR (1964). The simplified oral hygiene index. J Am Dent Assoc; 68:7-13 
25. Jolanta A., Vilma B (2009). An Assessment of Dental Treatment Need: An Overview of Available Methods and Suggestions for a New, Comparative Summative Index. J Public Health Dent; 69 (1): 24-8

26. Avasthi K, Bansal K and Mittal M. (2011). Oral Health Status of Sensory Impaired Children in Delhi and Gurgaon. International Journal of Dental Clinics; 3 (2): 21-23.

27. Mariam A H Khalaf; Kamal E M El-Motayam; Randa Y Abd El-Gawad and Abir A Omara (2015) .Oral Health Knowledge and Attitude of Caregivers and Oral Health Status of Children with Hearing Impairment Journal of American Science ;11(5):73-80

28. El Deeb A M R. (2011). Assessment of Oral Health Status and the Effect of Implementing Dental Health Education Program in a Group of Deaf Children. Master Thesis in Pediatric Dentistry, Faculty of Oral and Dental Medicine, Cairo University.
29. Ajami B A, Shabzendedar M, Rezay Y A, (2007). Dental Treatment Needs of Children with Disabilities. Journal of Dental Research, Dental Clinics, Dental Prospects; 1 (2): 93-98.

30. Tagelsir A, Eltigani $K$ and Nurelhuda M (2013). Oral health of visually impaired schoolchildren in Khartoum State, Sudan. BMC Oral Health ; 13:33.

31. Shetty DK, Gupta B, Patil A, Mali S (2019). Oral health status of hearing impaired individuals in a school in Vashi, Navi Mumbai. Int J Prev Clin Dent Res; 6:80-2.

32. Abhishek M, Radhika G, Saleha M, Shahnaz M (2015). Assessment of oral health status of children with special needs in Delhi, India. RSBO ;12(3):244-51

33. Juma O A, Eshraq Z E, Abdulwahab M A, Aesa A J (2019). Oral Health Status and Treatment Needs for Children with Special Needs: A Cross-Sectional Study. Association of Support to Oral Health Research - APESB; 19: 4877 